\title{
Ambientalização Acadêmica: a contribuição da pós-graduação para a sustentabilidade
}

\section{Academic Environmentalization: the graduate contribution for sustainability}

\section{Ambientalización Académica: la contribución del postgrado a la sostenibilidad}

http://dx.doi.org/10.221713/2358-2332.2016.v14.1257

Maria Luciana da Silva Nóbrega, doutora em Desenvolvimento Sustentável pela Universidade de Brasília (UnB), professora e pesquisadora-líder do Núcleo de Estudos em Sustentabilidade e Ambientalização da Universidade Federal do Vale do São Francisco (UNIVASF), campus Serra da Capivara, São Raimundo Nonato, PI, Brasil. E-mail: luciananobregaaa @ gmail.com.

Elimar Pinheiro do Nascimento, doutor em Sociologia pela Université René Descartes, França, professor associado do Centro de Desenvolvimento Sustentável e coordenador do Laboratório de Estudos sobre Turismo Sustentável da Universidade de Brasília (UnB), Brasília, DF, Brasil. E-mail: elimarcds@gmail.com.

\section{Resumo}

"Ambientalização" é a internalização das temáticas socioambientais nos diversos segmentos sociais, com intuito de melhorar a relação humana com o ambiente. "Ambientalização Acadêmica", por sua vez, é a institucionalização desse processo no âmbito universitário, por meio de mobilizações, produção sociotecnológica, preservação dos recursos naturais e convivência com o meio. O propósito deste artigo é evidenciar a prática da ambientalização nos programas de pós-graduação no Brasil nos últimos 30 anos, com a consolidação do conceito de desenvolvimento sustentável. O objetivo é demonstrar a "retroalimentação" existente entre a abordagem da sustentabilidade, sua influência na produção acadêmica e seu retorno à sociedade. Baseado no princípio da "responsabilidade compartilhada", analisamos a presença das demandas socioambientais na pós-graduação e a contribuição da produção acadêmica para a consolidação da cultura da sustentabilidade na sociedade.

Palavras-chave: Ambientalização. Universidade. Pós-Graduação. Sustentabilidade.

\footnotetext{
${ }^{1}$ Como citar: ABNT NBR 6023:2002 e incluir o DOI.
} 
Nóbrega e Nascimento / Ambientalização Acadêmica: a contribuição da pós-graduação para a sustentabilidade

\begin{abstract}
"Environmentalization" is the internalization of socio-environmental themes in different social segments, with the aim of improving the Human-Nature relationship. "Academic Environmentalization", in turn, is an initiative for sustainable action promotion, social technologies production, preservation and environmental harmony at universities. The purpose of this article is to address the sustainability in Brazilian graduate programs, in the last 30 years, since the consolidation of the sustainable development concept. The objective is to identify the feedback between the sustainability approach, its influence on academic production and its return to society. Having the "shared responsibility" as one of the pillars of the sustainable practices, we analyzed socio-environmental demands in postgraduate studies and the contribution of academic production to the consolidation of sustainability culture dissemination.
\end{abstract}

Keywords: Environmentalization. University. Graduate Studies. Sustainability.

\title{
Resumen
}

"Ambientalización" indica una internalización del tema Medio Ambiente en distintos ámbitos sociales, con propósito de mejorar la relación humana con el medio ambiente. La "Ambientalización Académica" es este proceso en las universidades, con discursos y acciones sostenibles, producción de tecnologías sociales, conservación y armonía con el medio ambiente. El objeto de este artículo es demostrar el enfoque de sostenibilidad en los estudios brasileños de postgrado en los últimos 30 años, desde la consolidación del concepto de desarrollo sostenible. El objetivo es demostrar la relación de "retroalimentación" existente en el enfoque de la sostenibilidad, la producción académica y su retorno a la sociedad, especialmente, en las prácticas destinadas a la cooperación y la difusión de la "responsabilidad compartida", uno de los pilares de la cultura de la sostenibilidad.

Palabras clave: Ambientalización. Universidad. Postgrado. Sostenibilidad.

\section{INTRODUÇÃO}

O alerta feito por Malthus (1798) sobre o descompasso entre o crescimento populacional e a produção dos meios de subsistência - e o possível caos à sobrevivência humana - apesar de controverso, foi um prenúncio da atual crise socioambiental. A teoria malthusiana tencionou o debate sobre a necessária "responsabilidade compartilhada", por isso a problemática socioambiental tem figurado nas pautas político-institucionais até a atualidade.

Mesmo a Revolução Verde pondo, momentaneamente, os alertas de Malthus nas calendas gregas, a teoria foi revisitada em 1972 com a publicação do relatório Limites do crescimento (MEADOWS et al., 1973) e com a realização da Conferência de Estocolmo. Desde então, a percepção da crise socioambiental ampliou. Novas abordagens surgiram a partir dos relatórios das conferências mundiais, das pesquisas das organizações independentes e das contribuições dos intelectuais, políticos e ambientalistas - estes últimos surgidos no contexto 
Nóbrega e Nascimento / Ambientalização Acadêmica: a contribuição da pós-graduação para a sustentabilidade

dos anos 1970. Uma dessas abordagens foi o entendimento da crise socioambiental como crise de percepção e atuação dos indivíduos. Esta perspectiva epistemológica propõe uma reconstrução da inter-relação entre os indivíduos e a natureza (CAPRA, 2001; LEFF, 2002; MORIN, 2005; GUATTARI, 2009).

Segundo a abordagem epistemológica, o enfrentamento da crise socioambiental começa por um amplo debate sobre sua complexidade e seus efeitos. Neste sentido, as instituições de ensino, em especial as universidades, têm dado sua contribução ao debate com inovação científica e formação de indivíduos, sobretudo na pós-graduação, pois pesquisa, inovação e formação lato sensu e stricto sensu integram sua base, uma vez que o debate e o estímulo à responsabilidade por uma cultura de sustentabilidade vêm somando-se à missão e aos objetivos da universidade. Passados 30 anos desde a gênese do conceito de desenvolvimento sustentável (COMISSÃO MUNDIAL SOBRE MEIO AMBIENTE E DESENVOLVIMENTO, 1991), a profusão dos programas de pós-graduação com a temática socioambiental é um sinal positivo vindo das universidades com relação à abordagem epistemológica para o enfrentamento da crise. Neste artigo, analisamos a "retroalimentação" existente entre a influência das demandas socioambientais na Ambientalização Acadêmica das práxis universitárias, em especial na pósgraduação, e, por sua vez, a contribuição da produção acadêmica para a consolidação de uma cultura orgânica de sustentabilidade na universidade, e, por fim, o retorno dessa produção acadêmica e a sua repercussão na sociedade.

\section{CRISE SOCIOAMBIENTAL}

$\mathrm{Na}$ Antiguidade, com Aristóteles (350 a.C.), a natureza era vista como autorregulatória, formando com o ser humano uma interdependência harmônica. No século XVII, o Novum Organum, de Francis Bacon, criticou a concepção grega de natureza, considerada "contemplativa", expondo o conceito moderno do "poder humano transformador". No auge do Racionalismo, Descartes propôs, com o método experimental, compreender o "funcionamento" da natureza. No Discurso sobre o método, de 1637, ele afirmou: "[...] conhecendo a força e a ação do fogo, da água, do ar, dos astros [...] poderíamos empregá-los em todos os usos para os quais são próprios e assim nos tornar como que senhores e possuidores da natureza" (DESCARTES, 1978, p. 113-114). Foi o auge da Revolução Científica, a vitória dos modernos sobre os antigos.

A crise socioambiental do século $\mathrm{XX}$ se tornou um problema geopolítico e socioeconômico. A imprudência de corporações promoveu algumas das maiores tragédias evitáveis da história ${ }^{2}$. Entre 1920 e 2005 , mais de 36 mil pessoas morreram em explosões e vazamentos (BRASIL; SANTOS, 2007) e milhões de animais foram contaminados, na maioria peixes e aves. Segundo Hobsbawm (1995), o século XX nasceu mergulhado em incertezas, fruto da herança moderna na crença da infalibilidade da Revolução Científica. Sobretudo após

\footnotetext{
${ }^{2}$ Contaminação da Baía de Minamata por metais pesados no Japão, em 1954; vazamento de 45 toneladas do pesticida metil isocianato em Bophal, Índia, em 1984; radiação em toda Rússia e parte da Europa pela usina nuclear de Chernobyl, na Ucrânia, em 1986; vazamento de 40,82 milhões de litros de petróleo do navio Exxon no Alasca, EUA, em 1989.
} 
a década de 1950, instala-se a generalização da crise, ou seja, a crise socioambiental não pode ser dissociada das demais, ela faz parte do "pacote", das "Décadas de Crises":

Ainda mais óbvia que as incertezas da economia e da política mundiais era a crise social e moral, refletindo as transformações pós-década de 1950 na vida humana, que também encontraram expressão generalizada, embora confusa, nessas Décadas de Crise. Foi uma crise das crenças sobre as quais se apoiava a sociedade moderna desde que os Modernos ganharam sua famosa batalha contra os Antigos, no início do século XVIII (HOBSBAWM, 1995, p. 20).

O projeto da Modernidade surgiu para atender eficientemente às necessidades humanas. Porém, culminou numa crise socioambiental global sem precedentes causada por mudanças climáticas $^{3}$, escassez de recursos naturais, consumismo e enorme geração de resíduos. A Revolução Científica não impediu a crise socioambiental. Logo, seria necessária uma mudança de paradigma para o seu enfrentamento: não crer e não depender somente das inovações científico-tecnológicas, mas promover outra abordagem, advinda do entendimento holístico da crise socioambiental, enquanto um problema epistemológico. Essa tem sido, em especial, uma missão conferida às instituições de ensino, onde a abordagem epistemológica encontra o seu locus privilegiado. O tratamento da problemática socioambiental de forma sistêmica tem encontrado espaço de articulação e proposições alternativas nas salas de aulas e na produção acadêmica, sobretudo nas abordagens do ensino, da extensão e da pós-graduação nas universidades.

\subsection{Crise socioambiental como problema epistemológico}

Ulrich Beck em seu livro World risk society (1999) argumenta que a Revolução Industrial da Primeira Modernidade, nos séculos XVIII e XIX, criou a "sociedade de risco", para que a produção e a distribuição de bens - assim como os riscos - ficassem "restritas" aos seus territórios. $\mathrm{O}$ risco de finitude dos recursos naturais para o consumo se tornou uma variável possível, porém desconsiderada. Já na Segunda Modernidade ${ }^{4}$, a compreensão dessa finitude, o comprometimento com a qualidade de vida e a ideia de "limite" passaram a ter evidência.

Apenas uma ressignificação da inter-relação entre os indivíduos e a natureza poderia superar a lógica do antropocentrismo moderno. Capra (2001) sugere uma visão sistêmicocomplexa na qual, "[...] em vez de tratar a teia da vida como mercadoria, a respeitássemos como o próprio contexto em que se desenrola a nossa existência" (CAPRA, 2001, p. 212). Na "complexidade ambiental", o ser se reposiciona por meio do saber (LEFF, 2002). A Modernidade limitou a natureza a um recurso e criou o paradigma "ter para ser". A crise socioambiental é, portanto, uma oportunidade de rever a lógica da satisfação baseada na finitude. A Teoria da Complexidade (MORIN, 2005) reforça a compreensão de que propostas

\footnotetext{
${ }^{3}$ Dentre elas, o aquecimento global pelo aumento de emissão de $\mathrm{CO}_{2}$ e dos gases de efeito estufa (GEEs) na atmosfera, medido pelo alargamento da ecological footprint (WACKERNAGEL; REES, 1996).

${ }^{4}$ Nessa fase, os riscos ecológicos, químicos, nucleares, genéticos e econômicos são "democráticos”, não respeitam fronteiras. Surge "uma nova forma de capitalismo, uma nova forma de economia, uma nova forma de ordem global, uma nova forma de sociedade e uma nova forma de vida pessoal" (BECK, 1999, p. 7).
} 
Nóbrega e Nascimento / Ambientalização Acadêmica: a contribuição da pós-graduação para a sustentabilidade

pedagógicas promovem mudança de hábitos e desenvolvem competências, capacidade de avaliação e participação.

Segundo Guattari (2009), para recuperar a visão socioambiental sistêmica é preciso articular ética e política. Sua "Ecosofia" ${ }^{5 "}$ está baseada em três ecologias: do meio ambiente, das relações sociais e da subjetividade humana. Pois, “[...] não haverá verdadeira resposta à crise ecológica a não ser em escala planetária e com a condição de que se opere uma autêntica revolução política, social e cultural" (GUATTARI, 2009, p. 9). Quanto à solução tecnológica, ele a trata como "um paradoxo lancinante", visto que mesmo diante do contínuo desenvolvimento de novas técnicas, as forças sociais estão incapazes de se apropriar desses meios e operacionalizá-los (GUATTARI, 2009, p. 12).

Mais uma vez, a história nos mostra que a solução tecnológica per se não é capaz de trazer uma resposta satisfatória, uma vez que lhe falte a mediação dos valores sociais. A universidade é a instituição onde essa razão é considerada, mediante a "retroalimentação" entre as demandas sociais recebidas, sua produção acadêmica e o retorno dessas demandas em produtos para a sociedade. A partir da atuação sociotecnológica da universidade, há a recuperação da visão socioambiental sistêmica, porque suas inovações tecnológicas tendem a considerar o equilíbrio entre o entendimento da complexidade ambiental, a busca pela inovação e o benefício da sociedade.

\subsection{A superação da crise: sustentabilidade e desenvolvimento sustentável}

Na década de 1960, surgiram alertas ${ }^{6}$ de uma crise socioambiental iminente. Os anos 1970 iniciaram com dois golpes na economia: a nova fase do industrialismo diante do colapso do sistema Bretton Woods ${ }^{7}$ e a crise de oferta do petróleo, principal commodity energética das economias desenvolvidas - com o primeiro e o segundo choque do petróleo, em 1973-1974 e 1979, respectivamente. Diante deste cenário, surgiu uma maré de proposições idealistas e abordagens alternativas ${ }^{8}$ que influenciou gerações de intelectuais. Em 1972, foi realizada na Suécia a Conferência das Nações Unidas sobre o Ambiente Humano ${ }^{9}$, chamada Conferência de Estocolmo. Foi a primeira a debater degradação, poluição "transfronteiriça" e as responsabilidades com o ambiente, tratando-as como questões de governança transnacional.

Nos anos seguintes, o tema passou para a esfera política, associando os planos de desenvolvimento ao aspecto socioambiental, tendo o "bem-estar social" um dos seus pilares. Em 1987, o relatório Nosso futuro comum trouxe a definição clássica de desenvolvimento

\footnotetext{
${ }^{5}$ Termo criado por Arne Naess, em 1972, em uma junção de Filosofia e Ecologia. Trata-se de um conjunto de regras e normas para se alcançar o equilíbrio ecológico. Outros expoentes: Gilles Deleuze e Michel Maffesoli.

${ }^{6}$ Em especial, a obra Silent Spring (CARSON, 1962), sobre o uso indiscriminado de pesticidas nos EUA e na Ásia, e outros trabalhos sobre o crescimento populacional, como A bomba populacional (EHRLICH, 1968), Tragédia dos comuns (HARDIN, 1968) e Limites ao crescimento (MEADOWS et al., 1973).

${ }^{7}$ Conjunto de regras sobre as relações comerciais estabelecido em julho de 1944, através da Conferência Monetária e Financeira das Nações Unidas, em Bretton Woods, New Hampshire (EUA).

8 "Ecologia profunda" (Arne Naess, em 1973), "Ecodesenvolvimento" (Maurice Strong e Ignacy Sachs, em 1973), "Tecnologias apropriadas" (Ernst F. Schumacher, em 1973), "Bioeconomia" (Georgescu-Roegen, em 1975), "Crescimento Zero" (Jan Tinbergen, em 1977), "Ecologia Política" (André Gorz, em 1979) e outras (BURSZTYN; BURZSTYN, 2012).

${ }^{9}$ Com representantes de 113 países, designou a criação do Programa das Nações Unidas para o Meio Ambiente (PNUMA) e elegeu o dia 5 de junho como o Dia Mundial do Meio Ambiente (BURSZTYN; BURSZTYN, 2012).
} 
sustentável, posteriormente consolidada como o "[...] desenvolvimento que satisfaz as necessidades do presente sem comprometer a capacidade das gerações futuras em satisfazer suas próprias necessidades" (COMISSÃO MUNDIAL SOBRE MEIO AMBIENTE E DESENVOLVIMENTO, 1991). Todavia, apesar de complexo pela sua estrutura interdisciplinar, interinstitucional e intergeracional, o conceito se mostrou vago, visto que não definiu os agentes responsáveis em "desenvolver" as metas para o "presente" e para o "futuro".

Diante disso, algumas definições e visões de sustentabilidade surgiram já contraditórias e ambíguas, por vezes irreconciliáveis, principalmente quanto aos limites do crescimento econômico e à finitude dos recursos ambientais. Segundo Moura (2002), as correntes "ecotecnocrática" (ou Economia Verde) e "ecossocial" (Ecodesenvolvimento) são exemplos de enfoques distintos. Contudo, as discussões e proposições são válidas, pois promovem o surgimento de ideias e pontos de vista enriquecedores a respeito da compreensão e aplicabilidade da proposta da sustentabilidade, visto que os problemas ambientais permanecem em profusão. Conceitos tão distintos como "convivencialidade" (ILLICH, 1973) e "decrescimento" (GEORGESCU-ROEGEN, 2012; LATOUCHE, 2009), são exemplos de proposições criativas e alternativas ao stablishment do conceito de desenvolvimento.

A sustentabilidade possui caminhos distintos, mas paralelos. No âmbito educacional, em especial no espaço acadêmico, o locus deste estudo, o envolvimento com as questões socioambientais tem ido além da adoção de um projeto pedagógico e atingido, dentre outros objetivos: as demandas dos segmentos sociais e políticos quanto às inovações e soluções, a participação das universidades na promoção da sustentabilidade e o atendimento aos interesses dos grupos financiadores e das sociedades científicas de fomento e pesquisa.

Resende (2013) destaca que o aspecto mais considerável da sustentabilidade é a redução das desigualdades e a promoção da educação, uma vez que perseguir os patamares de crescimento sem levar em conta a força propulsora da educação é um erro. Vemos o importante papel atribuído à universidade, em especial à pós-graduação, no âmbito da promoção da sustentabilidade: em sua função social, dotar a sociedade com inovação sociotecnológica; em sua função técnica, formar, com excelência, nas áreas e temáticas socioambientais (CUNHA, 1974).

\section{AMBIENTALIZAÇÃO}

"Ambientalização" indica uma internalização da temática socioambiental nas estruturas sociais, implicando transformações no Estado, nas organizações e nos indivíduos, consequentemente influenciando todas as áreas da sociedade. Segundo Lopes (2006), o termo é um neologismo que designa um processo fenomenológico de promoção de novos comportamentos. Sua gênese está ligada a cinco fatores:

1. A institucionalização da temática socioambiental, a partir de 1970 , e a realização das conferências (Estocolmo, Tbilisi, Rio-92 e outras);

2. Os conflitos locais em torno dos recursos naturais, que demandam ações de adaptação e novas relações sociais;

3. A Educação Ambiental (EA) como um código de conduta individual e coletivo;

4. A participação social nas questões socioambientais; 
Nóbrega e Nascimento / Ambientalização Acadêmica: a contribuição da pós-graduação para a sustentabilidade

5. Os aspectos ambientais como fonte de legitimidade e argumentação nos conflitos.

Para Gonzáles-Muñoz (2008), a ambientalização está ligada a um plano educacional, cuja prática escolar atua na interdisciplinaridade e na transversalidade indissociadas:

Dentro de uma visão sistêmica, própria à Educação Ambiental, todos os elementos do currículo devem preocupar-se com a Ambientalização e a forma que será projetada. A cooperação de todas as disciplinas é exigida, por isso todas devem ter algumas referências comuns, tendo isso como finalidade ou objetivos gerais do sistema educativo (GONZÁLES-MUÑOZ, 2008, p. 34).

Uma aplicação prática do conceito na área educacional chama-se "Ambientalização Curricular". O conceito foi elaborado em 2002, a partir da iniciativa do Programa Alfa ${ }^{10}$, promovido pela União Europeia. O programa envolveu 11 universidades, cinco europeias e seis latino-americanas. Destas, três são brasileiras: Universidade Estadual Paulista (Unesp), Universidade Estadual de Campinas (Unicamp) e Universidade Federal de São Carlos (UFSCar). Nesse contexto, foi criada a Rede de Ambientalização Curricular do Ensino Superior (Rede ACES). Os pesquisadores da Rede ACES elaboraram o Programa de Ambientalização Curricular do Ensino Superior: proposta de intervenções e análises do processo, com a finalidade de propor metodologias de análises para avaliar o grau de ambientalização curricular de suas instituições.

Para a Rede ACES, “ambientalização" é um processo complexo ligado ao ensino, como para Gonzáles-Muñoz. A Rede ACES se reporta aos marcos legais - planos, programas, políticas e resoluções - consolidados em cada país.

O enfoque da Rede ACES associa fortemente o marco teórico da ambientalização à reorientação curricular (FREITAS; OLIVEIRA, 2004), privilegiando as discussões das práticas pedagógicas e metodológicas, em um processo constante de internalização das questões ambientais nas instituições de ensino. Contudo, a ambientalização não pode ser uma ação de âmbito isolado, das práticas educacionais somente ou da universidade em si, mas deve se constituir em um conjunto de ações diversificadas e articuladas entre as instâncias acadêmicas - ensino, pesquisa e pós-graduação, extensão e gestão -, a universidade e a sociedade. É necessário que as práticas sustentáveis sejam mensuradas, avaliadas, revisitadas e atualizadas constantemente, contribuindo no estabelecimento de padrões e orientações de postura, assim como na formação de conceitos, trazendo aportes e agregando novos entendimentos.

A proposta da Figura 1, a seguir, evidencia os aspectos curriculares e metodológicos da Rede ACES para as Instituições de Ensino Superior (IES), no seu chamado “diagrama circular”:

10 O programa teve por objetivo traçar um plano de promoção da sustentabilidade no contexto universitário, chamada de Ambientalização Curricular dos Estudos Superiores (GELI, 2002). 
Figura 1 - Diagrama circular: as dez características do Estudo Ambientalizado da Rede ACES

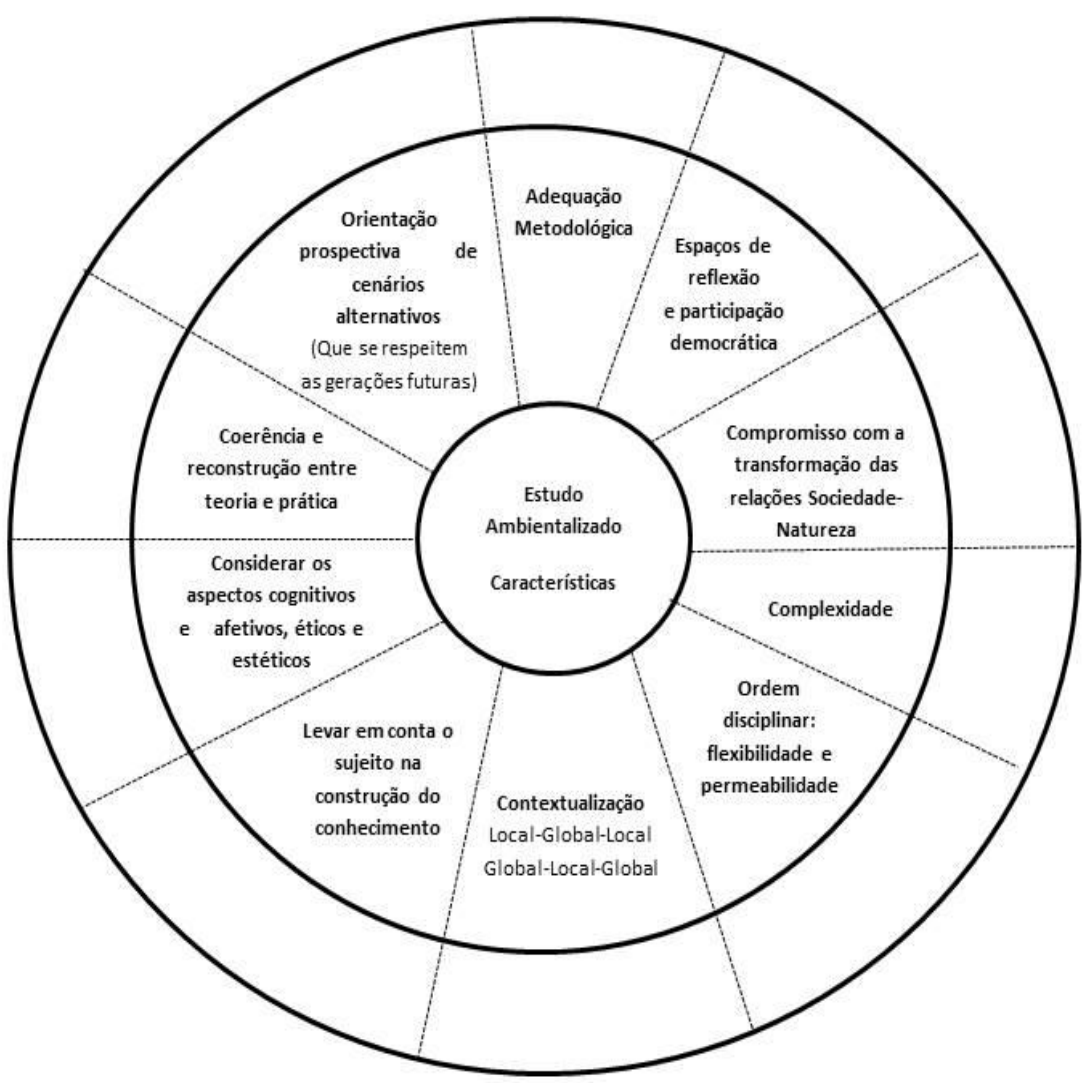

Fonte: OLIVERIA JÚNIOR et al (2003, p.41).

A ambientalização deve servir a uma mudança de posicionamento das instituições e dos indivíduos frente à necessidade de adaptação às realidades socioambientais. Segundo Sorrentino e Biasoli (2014), as instituições devem promover "[...] eixos transversais propiciadores de ambientalização" (SORRENTINO; BIASOLI, 2014, p. 40). O primeiro eixo deve corresponder ao diálogo sobre utopias e valores e o segundo eixo deve corresponder ao método, às regras e aos procedimentos claros de como fazer essa ambientalização.

É necessário que as universidades compreendam sua contribuição à sustentabilidade e que as expectativas e demandas por soluções ambientalizadas sejam atendidas. Assim como Sorrentino e Biasoli (2014), entendemos que a ambientalização deve promover uma integração entre as instâncias acadêmicas, não somente a mudança curricular e pedagógica, mas influenciar, sobretudo, a produção acadêmica advinda da pesquisa e da pós-graduação. E por fim, a ambientalização, deve exercer uma função retroalimentadora: trazer as demandas socioambientais para a universidade, influenciar as práticas acadêmicas e dotar a sociedade de inovações sustentáveis e sociotecnológicas. 
Nóbrega e Nascimento / Ambientalização Acadêmica: a contribuição da pós-graduação para a sustentabilidade

\section{AMBIENTALIZAÇÃO ACADÊMICA (AA)}

Segundo Buarque (2008), o desenvolvimento local "[...] leva ao dinamismo econômico e à melhoria da qualidade de vida da população" (BUARQUE, 2008, p. 27). O desenvolvimento sustentável busca uma sinergia entre qualidade de vida da população local, eficiência econômica e gestão pública eficiente. Três princípios garantem essa sinergia: governança, organização da sociedade e distribuição de ativos sociais. Tais medidas culminam na reorganização da economia e da sociedade locais e na conservação ambiental. Assim como o processo de desenvolvimento, a problemática socioambiental é complexa e requer ações interinstitucionais para promover soluções factíveis.

$\mathrm{Na}$ perspectiva da "responsabilidade compartilhada", as universidades possuem um importante papel nos planos de desenvolvimento regional e local, pois é no território que as coisas acontecem. A demanda pelo protagonismo e pela eficiência das universidades no enfrentamento à crise socioambiental é crescente. Por sua inovação e formação, elas podem contribuir efetivamente em dois pilares do desenvolvimento regional: subsidiando a organização da sociedade e na construção e distribuição de ativos sociais, dentre os quais o conhecimento. Outra demanda é na atuação em prevenção, precaução, mitigação e combate de diversos impactos socioambientais (BRASIL, 2012).

A partir dos novos conhecimentos e da inter-relação com demais órgãos e instituições que tratam dos diversos problemas socioambientais - segurança hídrica, produção de tecnologias sociais, combate às mudanças climáticas, preservação da biodiversidade, dentre outros -, é possível construir uma rede de informações e utilizá-la na ambientalização da formação acadêmica.

As universidades serão cada vez mais ambientalizadas, conforme o tratamento dado aos recursos naturais em todas as suas atividades seja mais sustentável e à medida que essa busca direcione suas práticas, sua inovação e sua produção acadêmica, em especial na pesquisa e pósgraduação. Será mais ambientalizada uma universidade que reduz permanentemente o uso de recursos naturais em suas práticas acadêmicas e, quando possível, os reutiliza, reciclando ou promovendo a destinação correta dos dejetos não reutilizáveis. O resultado esperado é que essas práticas desenvolvidas promovam a defesa do meio ambiente por meio do uso racional e parcimonioso dos recursos naturais.

Para contribuir com a ampliação do entendimento sobre a ambientalização das universidades, apresentamos a proposta da "Ambientalização Acadêmica" (NÓBREGA, 2017). A Ambientalização Acadêmica (AA) trata do processo de disseminação de práticas de defesa do meio ambiente e do uso sustentável dos recursos naturais no âmbito universitário, por meio do ensino e da extensão contextualizadas, da pesquisa e pós-graduação que priorize as tecnologias sociais e da gestão institucional ecoeficiente, de modo que essa prática beneficie toda a sociedade.

Para tanto, são necessárias algumas indagações sobre esse entendimento: as universidades estão cientes - e atuantes - quanto ao papel que lhes é conferido, o de ser um "espaço educador sustentável” (TRAJBER; SATO, 2010)? Como identificar e estimular seu protagonismo no desempenho e na disseminação das ideias e posturas sustentáveis? Como implantar nas universidades a "cultura do planejamento e resultados" quanto às soluções ecológicas? Como saber se temos uma práxis sustentável, além da retórica? Uma das formas é 
analisar sua atuação por meio da perspectiva da AA, e procurar observar algumas prerrogativas, tais como: exercer um protagonismo quanto à promoção da cultura da sustentabilidade, ao estímulo à Pesquisa, Desenvolvimento e Inovação (PD\&I) sociotecnológica, à convivência com o meio e envolver todas as instâncias acadêmicas: ensino, pesquisa e pós-graduação, extensão e gestão.

\section{A PÓS-GRAdUAÇÃo NA BUSCA PELO EQUILÍbRIO ENTRE INOVAÇÃo, FORMAÇÃO E SUSTENTABILIDADE}

O convite à participação das universidades nos planos de Desenvolvimento Regional Sustentável (DRS) vem sendo feito desde os anos de $1970^{11}$. Desde então, a menção nas propostas de institucionalização das demandas socioambientais aborda a sua contribuição para o DRS a partir de ações que promovam o equilíbrio "social, ambiental, econômico, geográfico e cultural” (SACHS, 1994) visando à qualidade de vidas das populações locais.

A atuação das universidades quanto à "responsabilidade compartilhada" no enfrentamento da crise socioambiental pode ser vista, sobretudo nos últimos 30 anos, com a propulsão e o surgimento dos Programas de Pós-Graduação (PPGs) nas chamadas Ciências Ambientais (COORDENAÇÃO DE APERFEIÇOAMENTO DE PESSOAL DE NÍVEL SUPERIOR, 2013; RIBEIRO, 2010), em especial desde a publicação do relatório Nosso futuro comum (COMISSÃO MUNDIAL SOBRE MEIO AMBIENTE E DESENVOLVIMENTO, 1991), da formação do conceito de desenvolvimento sustentável e da criação da Agenda 21 Global, que o institucionalizou. $\mathrm{O}$ processo das conferências, aliado à agenda global do desenvolvimento sustentável, consolidou a missão das universidades por seu protagonismo nas questões socioambientais.

O Brasil, na esteira da discussão, elaborou o I Plano Nacional de Pós-Graduação (PNPG, 1975-1979), que tratava da expansão da pós-graduação no país, considerando-a a partir de um planejamento estatal atrelado às políticas de desenvolvimento social e econômico (PHILIPPI JR; SOBRAL, 2012). Não houve momento mais favorável. O contexto dos anos 1970 e início de 1980 forneceu à pós-graduação brasileira a oportunidade de se reestruturar, principalmente na perspectiva das discussões socioambientais globais contemporâneas.

Além do aporte conceitual e teórico dos documentos e das conferências, outra ferramenta importante para a consolidação das temáticas socioambientais nos programas de pesquisa e pós-graduação veio também na década de 1980, mediante o subprograma Ciências Ambientais (CiAmb), do Programa de Apoio ao Desenvolvimento Científico e Tecnológico (PACDT) do Ministério da Ciência e Tecnologia, em parceria com a Coordenação de Aperfeiçoamento de Pessoal de Nível Superior (Capes) e o Conselho Nacional de Desenvolvimento Científico e Tecnológico (CNPq).

Atualmente, encontra-se em vigor o V PNPG (2011-2020), cujas diretrizes apontam para duas características: a abordagem interdisciplinar nos PPGs e a relevância dos temas socioambientais, uma evidência de que a ambientalização tem fortalecido a pós-graduação e

\footnotetext{
${ }^{11} \mathrm{O}$ marco desse protagonismo está na proposta de implantação da Educação Ambiental e a realização da Conferência de Tbilisi, em 1977, organizada pela Organização das Nações Unidas para a Educação, Ciência e Cultura (Unesco) e pelo Programa das Nações Unidas para o Meio Ambiente (PNUMA).
} 
Nóbrega e Nascimento / Ambientalização Acadêmica: a contribuição da pós-graduação para a sustentabilidade

vice-versa. Isso pode ser atestado pelo avanço da abordagem interdisciplinar no ensino, na pesquisa e na pós-graduação, em especial na ampliação dos cursos com foco na área socioambiental. Segundo Pereira e Nascimento (2016), no processo de 40 anos em que a interdisciplinaridade vem sendo implantada no Brasil, o período de 1999 a 2007 cresceu, reconheceu e institucionalizou práticas e experiências interdisciplinares (PEREIRA; NASCIMENTO, 2016). Neste mesmo período, os mais antigos cursos e programas na área socioambiental estavam se consolidando, a exemplo do Programa de Pós-Graduação em Ciência Ambiental da Universidade de São Paulo (Procam/USP), iniciado em 1989, ao mesmo tempo em que programas de outras universidades estavam se ampliando (PHILIPPI JR et al., 2000).

Em 1999, a Capes criou o Comitê de Avaliação Multidisciplinar, que em 2008 passou a ser designada Área Interdisciplinar, compondo a grande área Multidisciplinar. Tanto que, em 2011, por meio da Portaria n ${ }^{\circ}$ 81, de 6 de junho, foi criada a Coordenação de Área de Ciências Ambientais da Capes (CACiAmb), que engloba a Câmara I (Meio Ambiente e Agrárias). Desde 1999, o crescimento de cursos de pós-graduação da área ambiental, somente em universidades públicas no Brasil, foi de mais 300\%: de 16 cursos em 1999 para 72 cursos em 2011 (COORDENAÇÃO DE APERFEIÇOAMENTO DE PESSOAL DE NÍVEL SUPERIOR, 2013). Por sua vez, nas universidades privadas, na última década, o curso de Gestão Ambiental tem sido o $2^{\circ}$ mais procurado na modalidade $\mathrm{EaD}$ (educação à distância), atrás somente do curso de Pedagogia; é também o $2^{\circ}$ curso com maior número de concluintes entre os dez mais do Brasil, com 42,1\% dos matriculados (SINDICATO DAS ENTIDADES MANTENEDORAS DE ESTABELECIMENTOS DE ENSINO SUPERIOR NO ESTADO DE SÃO PAULO, 2015). A ampliação da oferta e da consolidação dos cursos de graduação na área socioambiental reverbera na pós-graduação, pois incentiva as universidades, tanto públicas quanto privadas, a investir na continuidade dos estudos e da produção acadêmica.

Outro aspecto a considerar na internalização das temáticas socioambientais na pósgraduação é a profusão de terminologias com as quais os PPGs têm se identificado, atestando a amplitude e o reconhecimento das diversas abordagens, que também demonstram a convergência e a transversalidade das áreas temáticas dos PPGs e, consequentemente, dos seus respectivos produtos de Ciência, Tecnologia e Inovação (CT\&I). Diante da sobreposição de termos que ocorre na identificação dos cursos, apresentamos o Gráfico 1, a seguir, demonstrando o percentual dos cursos por terminologia. Dividindo-os em quatro grupos, A, B, C e D, é possível observar que a predominância é dos Grupos A e B:

Gráfico 1 - Convergência e transversalidade dos cursos da área CACiAmb (2012) 


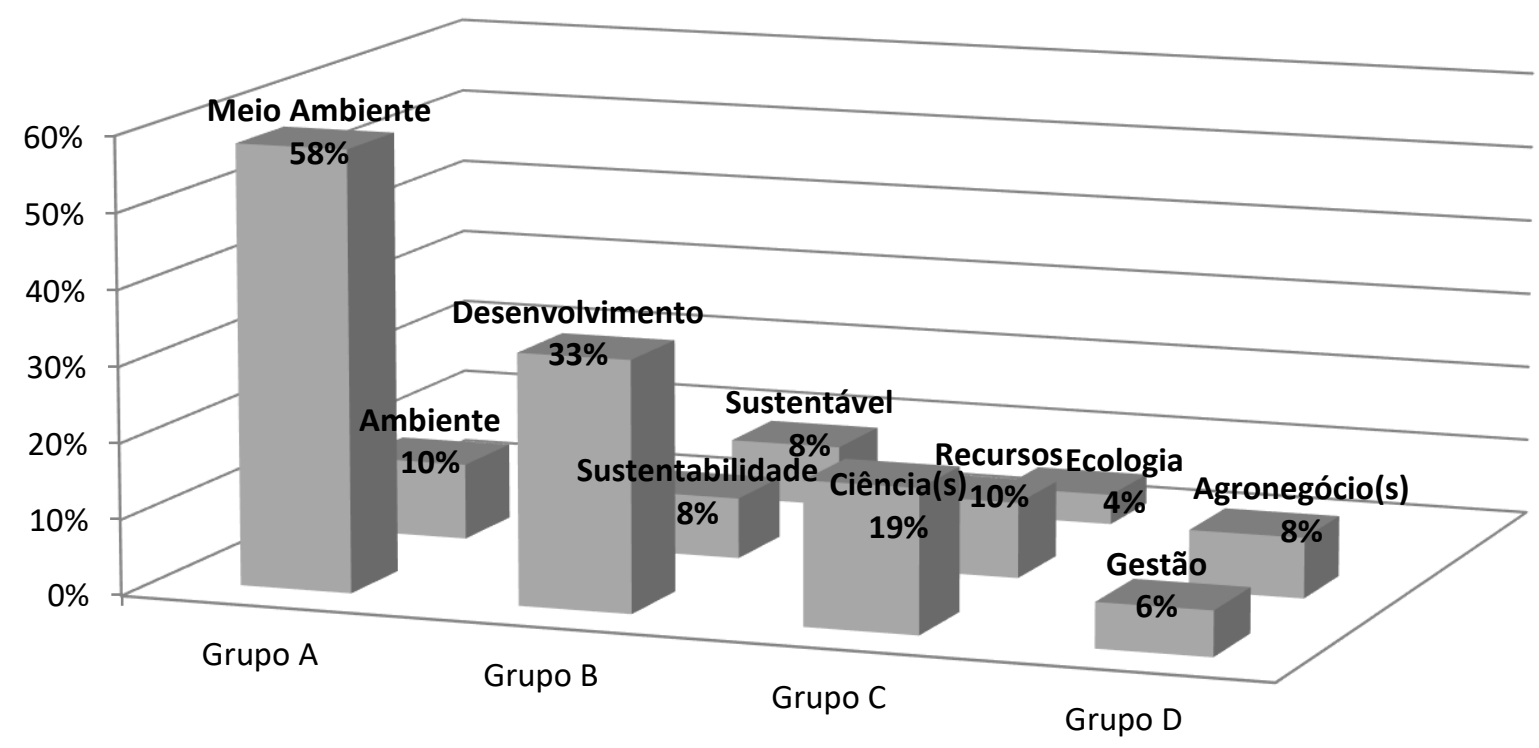

Fonte: Capes - CACiAmb, 2012, p. 9.

Na perspectiva da Ambientalização Acadêmica, a contribuição da pós-graduação tem sido significativa, tanto pelo cumprimento de sua função técnica na formação de excelência para atuar na perspectiva do DRS, quanto de sua função social como indicadora da contribuição das universidades para a organização da sociedade. Um aporte considerável, do ponto de vista metodológico, para subsidiar os PPGs, é a vasta produção teórica e jurídica disponível acerca de diretrizes orientadoras da política ambiental ${ }^{12}$. No contexto brasileiro, as universidades sempre figuram como parceiras dessa promoção. Outro aspecto positivo é disposição, cada vez maior, em diversificar e consolidar as temáticas socioambientais no contexto dos cursos e PPGs nas universidades. No Brasil, segundo dados da Capes do ano de 2013, o crescimento de cursos de pós-graduação em áreas multidisciplinares, como os PPGs interdisciplinares, foi de $150 \%$ entre 1976 e 2011, somente na área de Ciências Ambientais. Em dados mais recentes, como na Tabela 1, a seguir, é possível comparar o quadro atual dos PPGs e dos Cursos de Pós-Graduação (CPGs) da área Interdisciplinar, da Biodiversidade e das Ciências Ambientais e Ciências Agrárias (em destaque), com os demais afins:

\section{Tabela 1 - Áreas Multidisciplinar e CACiAmb na Pós-Graduação Capes (2016)}

\begin{tabular}{llcc}
\hline Área de avaliação & Total de PPGs & Total de CPGs \\
\hline - Biodiversidade & 141 & 232 \\
- Biotecnologia & 63 & 100 \\
- Ciência de Alimentos & 57 & 89 \\
- Ciências Agrárias & 224 & 369 \\
\hline
\end{tabular}

12 Resoluções e pareceres do Conselho Nacional de Educação (CNE/CP) n 2 e n ${ }^{\circ}$ 14, Política Nacional de Educação Ambiental, as Políticas Nacionais de Resíduos Sólidos, Recursos Hídricos, Mudanças Climáticas (PNMA), dentre outras. 
Nóbrega e Nascimento / Ambientalização Acadêmica: a contribuição da pós-graduação para a sustentabilidade

\begin{tabular}{lcc}
\hline - Ciências Ambientais & 117 & 148 \\
- Ciências Biológicas I & 63 & 112 \\
- Ciências Biológicas II & 74 & 130 \\
- Ciências Biológicas III & 36 & 65 \\
- Geociências & 57 & 99 \\
- Geografia & 64 & 99 \\
- Interdisciplinar & 344 & 447 \\
- Planejamento Urbano Regional Demografia & 47 & 63 \\
- Zootecnia/Recursos Pesqueiros & 69 & 103 \\
\hline
\end{tabular}

Fonte: Dados quantitativos de Programas Recomendados e Reconhecidos (CAPES, 2016).

Segundo dados do documento de área (CAPES, 2013), no contexto da pós-graduação brasileira, há maior concentração de programas das Ciências Ambientais nas regiões Sudeste $(30 \%)$ e Nordeste (24\%), enquanto a região Norte (14\%), a Centro-Oeste (15\%) e a Sul (17\%) ainda registram menor concentração. A distribuição dos cursos por tipologia indica que $27 \%$ são doutorados, 55\% mestrados acadêmicos e 18\% mestrados profissionais (CAPES, 2013). O papel da pós-graduação é evidente na medida em que nela reside a grande capacidade das universidades criarem novos conhecimentos que alimentem o processo de sustentabilidade universitária, local e regional. Em processos desta natureza, a tendência é que novas tecnologias e novos conhecimentos sejam produzidos e implantados, como ocorre atualmente, no campo das energias renováveis e da preservação dos recursos naturais.

Prova desse crescimento é a quantidade de grupos de pesquisa com essas duas temáticas no âmbito da pesquisa e da pós-graduação. No Brasil, segundo dados do Diretório dos Grupos de Pesquisa Lattes (DGP/CNPq), no censo realizado em 2010, estavam cadastrados 2.064 grupos de pesquisa (BRASIL, 2016). Em 2016, houve aumento de 528 grupos, passando para 2.592 grupos de pesquisa cadastrados. Um crescimento médio de quase $30 \%$ dos grupos, com destaque para a região Centro-Oeste, onde o aumento dos grupos de pesquisa foi acima das demais, na ordem de quase $40 \%$, conforme a Tabela 2 , a seguir, na qual detalhamos informações dos grupos por região, segundo dados dos censos DGP 2010 e 2016:

Tabela 2 - Grupos de pesquisa em recursos naturais no Brasil, por regiões (2010 e 2016)

\begin{tabular}{lcc}
\hline \multicolumn{1}{c}{ Regiões / Brasil } & Grupos de Pesquisa em 2010 & Grupos de Pesquisa em 2016 \\
\hline Centro-Oeste & $\mathbf{1 6 3}$ & $\mathbf{2 2 5}$ \\
Nordeste & $\mathbf{4 7 5}$ & $\mathbf{5 7 6}$ \\
Norte & $\mathbf{1 6 1}$ & $\mathbf{1 9 2}$ \\
Sudeste & $\mathbf{8 2 1}$ & $\mathbf{1 0 1 9}$ \\
Sul & $\mathbf{4 4 4}$ & $\mathbf{5 8 0}$ \\
\hline
\end{tabular}

Fonte: BRASIL, 2016.

A contribuição da pesquisa e pós-graduação universitária é significativa também na área de patentes de tecnologias sustentáveis ou tecnologias verdes. Na identificação das "Patentes Verdes", do Programa Piloto de Patentes Verdes do Instituto Nacional de Propriedade Industrial 
(INPI), em 2014, as universidades apresentaram uma produção considerável nessa modalidade e em diversas áreas, conforme o Gráfico 2, a seguir:

Gráfico 2 - Percentual de titulares de "Patentes Verdes", por categoria (INPI, 2014)

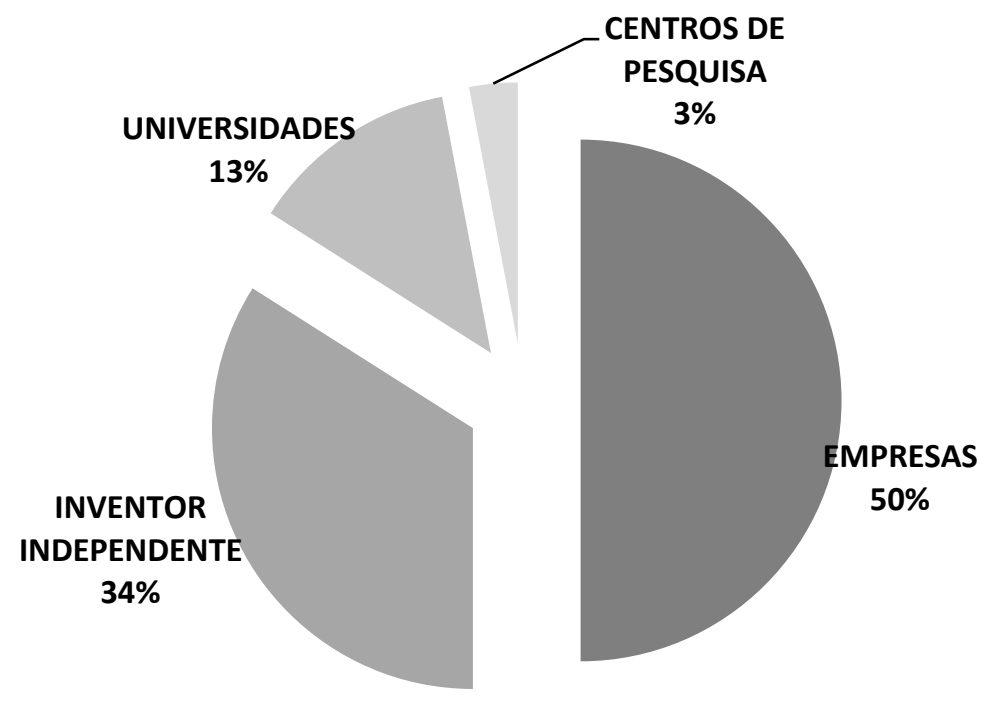

Fonte: INPI, 2014.

No Gráfico 3, a seguir, é possível observar as áreas nas quais as "Patentes Verdes" têm se sobressaído, segundo os dados do INPI:

Gráfico 3 - Percentual de "Patentes Verdes", por área de classificação (INPI, 2014)

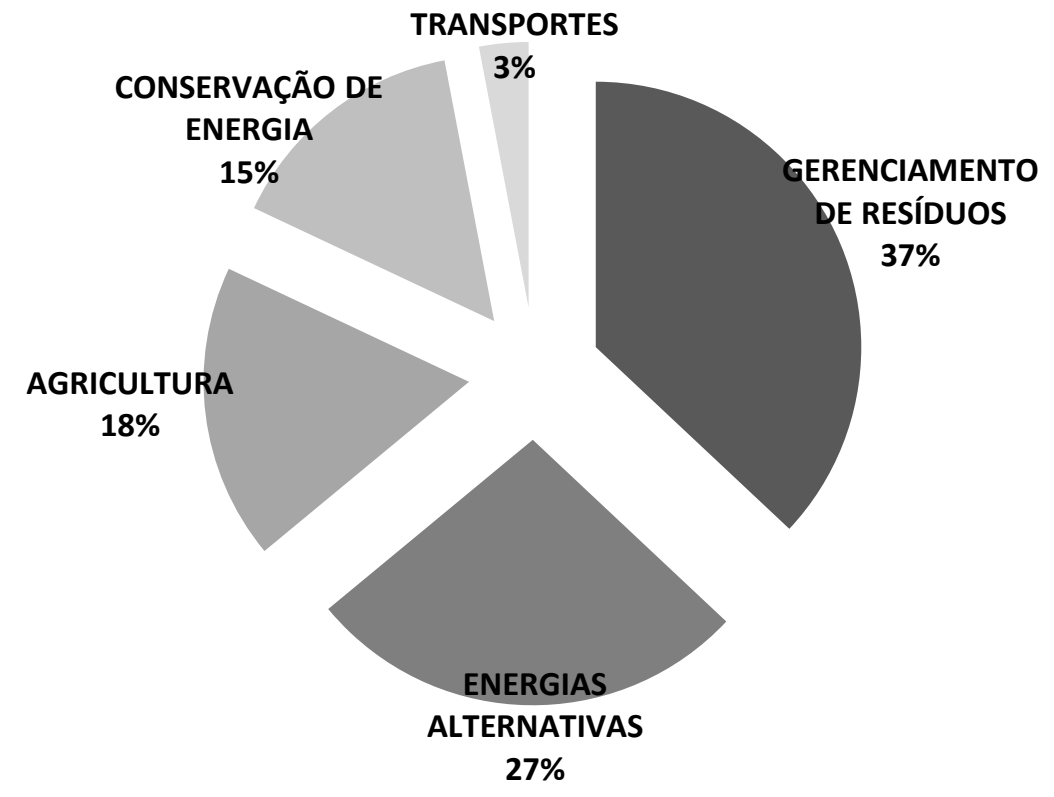

Fonte: INPI, 2014. 
Nóbrega e Nascimento / Ambientalização Acadêmica: a contribuição da pós-graduação para a sustentabilidade

Apesar de os esforços para adequar as demandas socioambientais da sociedade às funções acadêmicas, os desafios persistem. Entre eles, aqueles relacionados ao entendimento e ao modus operandi da interdisciplinaridade nas Ciências Ambientais (MALHEIROS et al., 2013; NASCIMENTO; AMAZONAS; VILHENA, 2013). Outro desafio é a falta de indicadores para a avaliação da ambientalização das e nas universidades brasileiras, o que ainda implica ineficiência nas práticas sustentáveis. Todavia, essa discussão está em andamento. Algumas iniciativas visando à construção de indicadores de sustentabilidade nas universidades estão acontecendo na América Latina, como a Rede de Indicadores de Sustentabilidade nas Universidades (RISU) e a Agenda Ibero-Americana para a Sustentabilidade nas Universidades (AISU), a se desenvolver no período 2015-2024 (SÁENZ, 2014). No Brasil, o momento também é propício a essa discussão, pois além da participação brasileira nas redes latinoamericanas, há iniciativas governamentais, como a implantação da Agenda Ambiental da Administração Pública (A3P) ${ }^{13}$, que poderá ser uma ferramenta estratégica para a adaptação das universidades ao atendimento das demandas socioambientais. Após a sua inclusão no plano plurianual 2004-2007, a A3P ficou definida “[...] como ação, no âmbito do programa de Educação Ambiental que busca implantar um novo referencial de sustentabilidade das atividades públicas" (BRASIL, 2009, p. 8).

No contexto internacional, o protagonismo e a responsabilidade socioambiental das universidades são acompanhados e avaliados por meio de rankings. Um dos mais importantes é o GreenMetric World University Ranking ${ }^{14}$, lançado em 2010. Os rankings refletem os esforços das universidades participantes em implantar políticas e programas de combate à mudança climática global. As premiações acontecem como forma de estimular a prática da Ambientalização Acadêmica. Organizações como a Association for the Advancement of Sustainability in Higher Education (AASHE) promovem premiações internacionais. O Campus Sustainability Award é uma dessas premiações entre universidades nos Estados Unidos, onde a sustentabilidade dentro dos campi universitários é uma prática corrente.

Apesar de o debate sobre a construção de indicadores de sustentabilidade estar no início, principalmente na América Latina, algumas práticas deveriam ser observadas como fundamentais para a sustentabilidade das e nas universidades. Dentre outros:

- O comprometimento político dos administradores superiores da universidade;

- A presença de um órgão de gestão socioambiental no organograma da instituição;

- A existência de um plano institucional para referenciar ações de planejamento e resultados, de prevenção de riscos socioambientais, entre outros;

- A retroalimentação entre as demandas regionais e as práticas acadêmicas (sobretudo da pesquisa e pós-graduação e da extensão).

\footnotetext{
13 A A3P foi criada em 1999. Possui uma cartilha com cinco eixos orientadores para a promoção da sustentabilidade no âmbito da administração pública. Contudo, não traz orientações específicas para as universidades.

${ }^{14}$ Iniciativa da Universitas Indonesia para estimular entre as universidades a promoção de seis critérios de sustentabilidade: "setting and Infrastructure", "energy and climate change”, "waste”, "water", "transportation” e "education”. Em 2015, participaram 407 universidades dos cinco continentes, entre elas oito brasileiras.
} 


\subsection{Oito passos para ambientalizar a universidade}

Quando as ações sustentáveis são evidenciadas nas práticas acadêmicas - nas pesquisas produzidas, nos processos de capacitação e difusão do conhecimento, nas tecnologias de gestão dos recursos naturais -, é possível afirmar que tais universidades possuem uma cultura orgânica de sustentabilidade e, consequentemente, participam da promoção do desenvolvimento regional sustentável. Neste sentido, a Ambientalização Acadêmica é uma das estratégias para se instalar uma cultura de sustentabilidade nas IES, com o apoio dos órgãos gestores das políticas educacionais e uma postura engajada por parte dos profissionais. Estes são outros desafios para as universidades: operacionalizar a prática da ambientalização, consolidar a temática socioambiental e promover a sustentabilidade. Isso significa ir além de uma componente curricular, é necessário alcançar todas as instâncias acadêmicas, estimulando o envolvimento da comunidade científico-acadêmica nas pesquisas, publicações e participação política.

Para promover a ambientalização nas universidades, deve-se investir em ações de impacto. Por isso propomos oito ações básicas que apontamos como os oito pilares da Ambientalização Acadêmica:

1. Produzir, no âmbito da pós-graduação, uma visão de PD\&I sociotecnológica, contextualizada e acessível, utilizando os padrões internacionais ${ }^{15}$ de uso eficiente e gestão dos recursos naturais;

2. Investir em estruturas e instalações adaptadas às realidades geoclimáticas para maior aproveitamento dos recursos naturais;

3. Consolidar pactos de cooperação com organizações, nacionais e internacionais, nas áreas estratégicas de tecnologia e informação, oportunizando às comunidades o acesso às inovações;

4. Ampliar a participação e a responsabilidade social da universidade nas políticas públicas, junto aos stakeholders (públicos de interesse) e tomadores de decisão;

5. Promover mobilizações, campanhas e processos formativos continuados e de Educação Ambiental sobre "uso, aproveitamento e gestão dos recursos naturais" nas modalidades de extensão, capacitação, graduação e pós-graduação;

6. Instalar Estações de Tratamento de Água (ETA) e Estações de Tratamento de Esgoto (ETE), visando à autossuficiência hídrica, à independência dos sistemas municipais, à economia no orçamento das IES e à utilização didática desse espaço como laboratórios para aulas, pesquisas e capacitações;

7. Instalar Estações de Tratamento de Resíduos Químicos (ETRQ) para tratar dos resíduos poluidores gerados nos laboratórios e descartá-los adequadamente, gerando economia na manutenção das redes de água e esgoto, consequentemente evitando sua contaminação;

8. Implantar a institucionalização da sustentabilidade, com ações diversas como a elaboração de um Plano Ambiental Institucional (PAI) para nortear as práticas sustentáveis na universidade, a preservação dos recursos naturais existentes, a criação

\footnotetext{
15 Advindos das redes e organizações tais como ACES, RISU, GreenMetric, AASHE, Higher Education and Research for Sustainable Development (HESD), entre outras.
} 
Nóbrega e Nascimento / Ambientalização Acadêmica: a contribuição da pós-graduação para a sustentabilidade

de programas de pós-graduação nas temáticas socioambientais regionais prioritárias, entre outras.

Embora a relação entre a temática socioambiental e a atuação universitária não seja recente, continua a ser um dilema. A universidade adentrou o século XXI com o paradigma da excelência socioambiental a rodear as instituições:

\footnotetext{
A universidade deve assumir sua responsabilidade dentro do processo de fortalecimento da democracia e formação de cidadãos autônomos. Para isso, o diálogo entre as disciplinas, a sustentabilidade e o compromisso social são conceitos de referência permanente (BARBIERO, 2012, p. 7).
}

Para assumir tamanha responsabilidade aguardada pela sociedade, é preciso uma ferramenta eficaz que avalie e oriente suas práticas para além do currículo. Aliando e avaliando o impacto das universidades em um âmbito de desenvolvimento sustentável é possível obter uma dimensão real e eficiente da sua atuação nesse papel social.

Logo, para garantir que as universidades sejam agentes dessa mudança de comportamento na questão socioambiental, é necessário definir instrumentos de promoção e avaliação de suas práticas ambientalizadas. Segundo Sachs (2002), o caminho é promover a sustentabilidade em todos os níveis: social, ambiental, econômica, política, em consonância com a proposta da sustentabilidade do sistema internacional para "[...] o estabelecimento de um sistema de administração para o patrimônio comum da humanidade" (SACHS, 2002, p. 72). Para ele, é necessário o estabelecimento de critérios de sustentabilidade, que podem auxiliar na construção de indicadores, baseados em oito dimensões ou aspectos promotores de qualidade: social, cultural, ecológica, ambiental, territorial, econômico, política nacional e política internacional. A lógica dos critérios de avaliação da sustentabilidade pode assessorar as universidades na verificação de suas ações nesse campo, avaliando sua contribuição no estabelecimento de um marco regulatório, proposto inicialmente pela Educação Ambiental e também seguido pela Ambientalização Acadêmica.

Os problemas ambientais demandam uma coalização para uma governança global, já que a natureza não reconhece as fronteiras políticas e econômicas impostas pelo ser humano. Conforme Veiga (2013), além das organizações, o envolvimento dos interlocutores da sociedade civil e das comunidades científicas aumenta o grau de legitimidade do processo multilateral de negociações. Ou seja, nenhuma instituição relevante pode ficar fora dessa nova coalizão de "governança global do desenvolvimento", que, conectada à preocupação com a biosfera, forma uma proposta de "governança ambiental global".

Esta é a contribuição da Ambientalização Acadêmica: tornar-se um processo contínuo de avaliação da prática universitária, perseguindo o ideal de promover a sustentabilidade dos recursos naturais pela ecoeficiência e autossuficiência e de gerar recursos econômicos próprios, até se tornar uma cultura orgânica nessas instituições, tanto quanto sua missão de ensinar ou sua vocação em pesquisar, inovar e interagir com as comunidades.

\section{CONSIDERAÇÕES FINAIS}

A década de 1970 e suas mudanças econômicas, políticas e intelectuais agregaram novos elementos na inter-relação sociedade e natureza. A percepção da crise socioambiental trouxe a 
noção da "responsabilidade compartilhada" como um princípio civilizatório a ser perseguido. A ideia de um projeto de vida com qualidade para todos em um planeta comum tem se configurado como a grande utopia no século XXI, assim como a participação engajada das instituições, tais como as universidades.

Como apresentado no decorrer deste artigo, apesar do crescimento dos cursos de pósgraduação com foco nas temáticas socioambientais e sua vasta produção acadêmica, as universidades ainda têm um grande desafio a sua frente: intensificar o diálogo entre as áreas inter e multidisciplinares para a troca de experiências e divulgação do conhecimento gerado (CAPES, 2013). Uma ação estratégica para promover a sustentabilidade e os PPGs nas áreas socioambientais - somada às estratégias já existentes, como a criação da área de Ciências Ambientais da Capes, a CACiAmb, em 2011 - seria a criação dos fóruns nacionais sobre Sustentabilidade Universitária (SU), como forma de integrar as instituições e seus programas de pesquisa e pós-graduação, subsidiar órgãos governamentais e demais instâncias políticas, animar o debate e implantar propostas de divulgação e acompanhamento das boas práticas de cada instituição. A avaliação dessas ações, seus impactos locais e sua replicação em outros contextos, quando possível, contribuirá sobremaneira para a construção de uma rede da sustentabilidade entre as universidades.

Este artigo buscou traçar uma evolução do conceito de "ambientalização", atendo-se ao âmbito educacional-institucional, especialmente na Ambientalização Curricular. Com uma breve contextualização, é possível observar que, apesar de o conceito ser inteligível e relevante, falta-lhe robustez e pragmatismo. Os argumentos são bem construídos e, de certo, não há quem seja contra a sua relevância ou urgência. Contudo, a falta de indicadores, da descrição de medidas práticas, factíveis, e de resultados pode tornar o conceito somente mais um "belo discurso", com o risco de se tornar inócuo.

Diante disso, propomos que a Ambientalização Acadêmica seja uma meta para a efetiva promoção da sustentabilidade no âmbito universitário, por meio de critérios e indicadores que considerem três aspectos indissociáveis: "ecoeficiência", autossuficiência e "eco-nomia", garantindo que as metas sejam alcançadas pelas universidades. Tais metas devem ser conscientes e factíveis:

- "Ecoeficiência" na implantação de equipamentos e infraestrutura que promovam a redução do consumo e de gastos financeiros com recursos naturais, como água e energia;

- Autossuficiência quanto ao tratamento de água e esgoto e geração de energia;

- "Eco-nomia" com ações de empreendedorismo universitário, em que o orçamento que fosse poupado com os gastos em tratamento de água, esgoto e em energia elétrica pudessem ser revertidos na pesquisa e na inovação sociotecnológica, incluindo a venda de energia excedente e o estabelecimento de marcas e patentes.

Associar a promoção da sustentabilidade a uma "cultura do planejamento e resultados" é a proposta que apresentamos com a Ambientalização Acadêmica, com indicadores definidos que permitam mensurar a sua operacionalização. Nessa perspectiva, a universidade estará ambientalizada quanto mais perceptível forem os seus resultados nos campos ecológico, energético e econômico, e quanto mais envolvida a comunidade acadêmica estiver com o ensino, a pesquisa e a pós-graduação, a extensão e a gestão, numa visão participativa dessas 
Nóbrega e Nascimento / Ambientalização Acadêmica: a contribuição da pós-graduação para a sustentabilidade

ações. Neste processo o papel da pós-graduação é fundamental, pois nela reside a capacidade de produção de novos conhecimentos que poderão ser apropriados pela gestão universitária com a finalidade de criar práticas sustentáveis no interior dos campi universitários e para seus contextos de inserção.

Processos significativos já ocorrem em algumas universidades, a exemplo da Universidade Federal de Lavras (UFLA/MG), uma das oito frequentes participantes brasileiras do GreenMetric Ranking (INDONESIA, 2015), considerada a $38^{\text {a }}$ universidade mais sustentável do mundo e a detentora do $1^{\text {a }}$ lugar entre as universidades brasileiras nos últimos cinco $\operatorname{anos}$ (2012 a 2016). Não por acaso, os maiores investimentos da UFLA na sua ambientalização residem na adequação de sua infraestrutura à realidade geoclimática, na criação de centros de pesquisa e de práticas extensivas e na pós-graduação, em especial na preservação e estudo dos recursos naturais, sobretudo dos recursos hídricos.

\section{Referências}

BARBIERO, A. Apresentação. In: NASCIMENTO, E. P.; PENA-VEGA, A. (Orgs.). As novas dimensões da universidade: interdisciplinaridade, sustentabilidade e inserção social. Rio de Janeiro: Garamond, 2012. p. 7-8.

BECK, U. World risk society. Cambridge: Polity Press, 1999.

BRASIL. Ministério do Meio Ambiente. Agenda Ambiental da Administração Pública (A3P). Brasília, DF: MMA, 2009.

BRASIL. Ministério da Educação. Resolução no 2, de 15 de junho de 2012. Estabelece as Diretrizes Curriculares Nacionais para a Educação Ambiental. Brasília, DF: MEC, 2012. Disponível em: $<$ http://portal.mec.gov.br/index.php?option=com_docman\&view=download\&alias=10988rcp002-12-pdf\&category_slug=maio-2012-pdf\&Itemid=30192>. Acesso em: 20 out. 2015.

BRASIL. Ministério da Ciência, Tecnologia, Inovações e Comunicações. Diretório dos Grupos de Pesquisa no Brasil Lattes. Brasília, DF: Conselho Nacional de Desenvolvimento Científico e Tecnológico, 2016. Disponível em: <http://dgp.cnpq.br/dgp/faces/consulta/consulta_parametrizada.jsf>. Acesso: 4 out. 2016.

BRASIL, A. M.; SANTOS, F. Dicionário: o ser humano e o meio ambiente de A a Z. 4. ed. São Paulo: Brasil Sustentável, 2007.

BUARQUE, S. C. Construindo o desenvolvimento local sustentável. 4. ed. Rio de Janeiro: Garamond, 2008.

BURSZTYN, M. A.; BURSZTYN, M. Fundamentos de política e gestão ambiental: caminhos para a sustentabilidade. Rio de Janeiro: Garamond, 2012.

CAPRA, F. A teia da vida. São Paulo: Cultrix, 2001. 
CARSON, R. Silent spring. Boston: Houghton Mifflin, 1962.

COMISSÃO MUNDIAL SOBRE MEIO AMBIENTE E DESENVOLVIMENTO. Nosso futuro comum. Rio de Janeiro: FGV: CMMDA, 1991.

COORDENAÇÃO DE APERFEIÇOAMENTO DE PESSOAL DE NÍVEL SUPERIOR. Documento de Área CACiAmb 2012. Brasília, DF: CAPES, 2012. Disponível em: http://ppgagro.posgrad.ufsc.br/files/2012/05/Documento-Area-CACiAmb-29Agosto20121.pdf. Acesso em: 26 out. 2016.

Documento de Área 2013. Brasília, DF: CAPES, 2013. Disponível em: <http://www.capes.gov.br/images/stories/download/avaliacaotrienal/Docs_de_area/Interdiscip linar_doc_area_e_comiss\%C3\%A3o_ATT27SET.pdf >. Acesso em: 24 out. 2016.

Dados quantitativos de programas recomendados e reconhecidos. Brasília, DF:

CAPES, $2016 . \quad$ Disponível em: <https://sucupira.capes.gov.br/sucupira/public/consultas/coleta/programa/quantitativos/quantit ativoAreaAvaliacao.jsf>. Acesso em: 20 out. 2016.

CUNHA, L. A. C. R. A Pós-Graduação no Brasil: função técnica e função social. Revista de Administração de Empresas, Rio de Janeiro, v. 14, n. 5, p. 66-70, set./out. 1974.

DESCARTES, R. Discurso sobre o método. São Paulo: Hemus, 1978.

EHRLICH, P. R. The population bomb. New York: Random House, 1968.

FREITAS, D.; OLIVEIRA, H. T. Uma reflexão sobre o valor do trabalho desenvolvido pela Rede ACES no período de sua implementação. In: GELI, A. M.; JUNYENT M.; SÁNCHEZ, S. (Orgs.). Ambientalización curricular de los estudios superiores: acciones de intervención y labance final del proyecto de ambientalización curricular de los estudios superiores. Girona: Universitat de Girona, 2004. v. 4, p. 305-319.

GELI, A. M. Universidad, sostenibilidad e ambientalización curricular. In: GELI, A. M.; ARBAT, E. (Orgs.). Ambientalización curricular de los estúdios superiores: aspectos ambientales de las universidades. Girona: Universitat de Girona, 2002. p. 15-18.

GEORGESCU-ROEGEN, N. O decrescimento: entropia, ecologia, economia. São Paulo: Senac, 2012.

GONZÁLEZ-MUÑOZ, M. D. C. Principales tendencias y modelos de la Educación Ambiental en el sistema escolar. Revista Iberoamericana de Educación, Madrid, n. 11, 2008. p. 13-74.

GUATTARI, F. As três ecologias. 20. ed. Campinas: Papirus, 2009.

HARDIN, G. The Tragedy of the Commons. Science Magazine, Washington, DC, v. 162, n. 3859, 1968. p. 1243-1248.

HOBSBAWM, E. Era dos extremos: o breve século XXI. São Paulo: Cia das Letras, 1995. 
Nóbrega e Nascimento / Ambientalização Acadêmica: a contribuição da pós-graduação para a sustentabilidade

ILLICH, I. A convivencialidade. Lisboa: Publicações Europa-América, 1973.

INSTITUTO NACIONAL DE PROPRIEDADE INDUSTRIAL. Patentes verdes. Brasília, DF: INPI, 2014. Disponível em: <http://www.inpi.gov.br/menu-servicos/patente/patentesverdes-v2.0>. Acesso em: 10 maio 2017.

LATOUCHE, S. Pequeno tratado do decrescimento sereno. São Paulo: WMF, 2009.

LEFF, E. Epistemologia ambiental. São Paulo: Cortez, 2002.

LOPES, J. S. L. Sobre processos de Ambientalização dos conflitos e sobre dilemas da participação. Horizontes Antropológicos, Porto Alegre, ano 12, n. 25, 2006. p. 31-64.

MALHEIROS, T. F. et al. Os desafios do tema sustentabilidade no ensino da Pós-Graduação. RBPG, Brasília, DF: v. 10, n. 21, out. 2013. p. 537-552.

MALTHUS, T. An essay on the principle of population. London: St. Paul's Church, 1798.

MEADOWS, D. H. et al. Limites do crescimento. São Paulo: Perspectiva, 1973.

MORIN, E. Educação e complexidade: os sete saberes e outros ensaios. São Paulo: Cortez, 2005.

MOURA, L. G. V. Indicadores para a avaliação da sustentabilidade em sistemas de produção da agricultura familiar. Dissertação (Mestrado em Desenvolvimento Rural) Programa de Pós-Graduação em Desenvolvimento Rural, Universidade Federal do Rio Grande do Sul, Porto Alegre, 2002.

NASCIMENTO, E. P.; AMAZONAS, M.; VILHENA, A. Sustentabilidade e interdisciplinaridade: inovações e desafios dos Programas de Pós-Graduação em Ambiente e Sociedade - o caso do Centro de Desenvolvimento Sustentável da Universidade de Brasília. RBPG, Brasília, DF, v. 10, n. 21, out. 2013. p. 665-695.

NÓBREGA, M. L. S. Ambientalização Acadêmica: Um estudo comparativo das práticas sustentáveis em Segurança Hídrica entre universidades brasileiras (UFLA e UFCG) e norteamericanas (ASU e UCLA). Tese (Doutorado em Desenvolvimento Sustentável) - Programa de Pós-Graduação em Desenvolvimento Sustentável, Universidade de Brasília, Brasília, DF, 2017.

OLIVEIRA JUNIOR, W. M. et al. As 10 características em um diagrama circular. In: JUNYENT, M.; GELI, A. M.; ARBAT, E. (Eds.). Ambientalización Curricular de los Estudios Superiores: aspectos Ambientales de les universidades. 2. ed. Girona: Universitat de Girona, v. 2, , 2003. p. 35-55.

PEREIRA, E. Q.; NASCIMENTO, E. P. A interdisciplinaridade nas universidades brasileiras. Redes, Santa Cruz do Sul, v. 21, n. 1, jan./abr. 2016. p. 209-232.

PHILIPPI JR, A.; SOBRAL, M. C. M. Contribuição da Pós-Graduação brasileira para o desenvolvimento sustentável: CAPES na Rio+20. Brasília, DF: Capes, 2012. 
PHILIPPI JR, A. et al. Interdisciplinaridade em ciências ambientais. São Paulo: Signus, 2000.

RESENDE, A. L. Os limites do possível. São Paulo: Portfolio-Penguin, 2013.

RIBEIRO, W. C. (Org.). Práticas socioambientais na Pós-Graduação Brasileira. São Paulo: Annablume, 2010.

SACHS, I. Estratégias de transição para o século XXI: desenvolvimento e meio ambiente. São Paulo: Nobel, 1994.

Caminhos para o desenvolvimento sustentável. Rio de Janeiro: Garamond, 2002.

SÁENZ, O. Panorama de la sostenibilidad en las Universidades en América Latina y El Caribe. In: RUSCHEINSKY, A. et. al. (Orgs.). Ambientalização nas instituições de educação superior no Brasil: caminhos trilhados, desafios e possibilidades. São Carlos: USP, 2014. p. 23-38.

SINDICATO DAS ENTIDADES MANTENEDORAS DE ESTABELECIMENTOS DE ENSINO SUPERIOR NO ESTADO DE SÃO PAULO. Mapa do ensino superior no Brasil 2012/2013. São Paulo: SEMESP, 2015. p. 6-15.

SORRENTINO, M.; BIASOLI, S. Ambientalização das instituições de educação superior: a Educação Ambiental contribuindo para a construção de sociedades sustentáveis. In: RUSCHEINSKY, A. et al. (Orgs.). Ambientalização nas instituições de educação superior no Brasil. São Carlos: USP, 2014. p. 39-46.

TRAJBER, R.; SATO, M. Escolas sustentáveis: incubadoras de transformações nas comunidades. Revista Eletrônica do Mestrado em Educação Ambiental, Porto Alegre, p. 70-78, 2010. Volume especial.

INDONESIA. Overall Ranking 2015. Depok: Universitas Indonesia, 2015. Disponível em: <http://greenmetric.ui.ac.id/overall-ranking-2015/>. Acesso em: 24 out. 2016.

VEIGA, J. E. A desgovernança mundial da sustentabilidade. São Paulo: Editora 34, 2013.

WACKERNAGEL, M.; REES, W. Our Ecological Footprint: Reducing Human Impact on the Earth. Gabriola Island: New Society Publishers, 1996.

Recebido em 18/10/2016

Aprovado em 15/05/2017 